\title{
Modeling and Simulation the Influence of Solid Carbon Formation on SOFC Performance and Degradation
}

\author{
V. Yurkiv ${ }^{\mathrm{a}, \mathrm{b}}$, A. Latz ${ }^{\mathrm{a}, \mathrm{c}}$ and W. G. Bessler ${ }^{\mathrm{b}, \mathrm{d}}$ \\ ${ }^{a}$ German Aerospace Centre (DLR), Institute of Technical Thermodynamics, 70569 \\ Stuttgart, Germany \\ ${ }^{b}$ Institute of Thermodynamics and Thermal Engineering (ITW), University of Stuttgart, \\ 70550 Stuttgart, Germany \\ ${ }^{c}$ Helmholtz Institute Ulm (HIU), Electrochemical Energy Storage, 89081 Ulm, Germany \\ ${ }^{\mathrm{d}}$ Offenburg University of Applied Sciences, 77652 Offenburg, Germany
}

\begin{abstract}
An elementary kinetic model is established to represent the coupled behavior of (electro)-chemistry, transport and degradation processes in the porous Ni/YSZ anode of solid oxide fuel cells (SOFC). The model is applied to support the development and evaluation of solid carbon formation mechanisms at Ni/YSZ anodes. The simulations of cells operated on partially reformed hydrocarbons show that performance and degradation are influenced significantly by the operation temperature and applied potential. Specifically, at OCV and high temperature (1023 K), a surface carbon layer is formed which covers $\mathrm{Ni}$ surface and $\mathrm{Ni}$ three-phase boundary, blocking heterogeneous and charge-transfer reactions. However, at lower temperature $(923 \mathrm{~K})$ carbon growth mainly proceeds inside of anode porous phase leading to significant diffusion polarization. Literature experimental data is used for validation of the model.
\end{abstract}

\section{Introduction}

Solid oxide fuel cells (SOFC) are a promising technology for supplying electrical energy for future demands. Due to many advantages such as high efficiency, low emissions, low noise, reliability, and fuel flexibility, it is expected that SOFC will play a major role in future energy conversion technologies (1). Being a high-temperature electrochemical device, SOFC can easily be operated on hydrocarbon fuels (e.g. methane, propane, butane) (2,3). However, SOFC operations on hydrocarbons suffer from the formation of solid carbon inside the electrode, which causes the degradation of cells. Therefore, understanding the origin and evolution of degradation processes, which typically take place on micro- and nanoscales, is essential in order to develop a long-term-operating SOFC technology.

The process of carbon formation at Ni/YSZ-based SOFC anodes has been investigated for many years $(2,4,5)$. It was identified that the type and amount of formed carbon at the Ni/YSZ anode depends upon many factors, for example, types of fuel, anode morphology, steam-to-carbon ratio, operating conditions etc. This was shown by a pioneering study of Bartholomew (6), who described five major carbon types forming on Ni such as adsorbed, carbide, polymeric, graphitic, vermicular and filaments. Generally, 
under typical SOFC working conditions, all of these carbon types can be classified into two major formation mechanisms: $(i)$ heterogeneously formed carbon that grows on nickel catalytic surface primary as a film, blocking heterogeneous and electrochemistry, and (ii) homogeneously/heterogeneously formed soot (pyrolytic carbon), which blocks pores increasing mass transfer resistance (7).

The model developed in this work represents coupled processes of chemistry, transport and degradation mechanisms at the Ni/YSZ-based SOFC anode. The present approach incorporates elementary heterogeneous chemical reactions, electrochemical charge-transfer, multicomponent porous-phase and channel-phase transport, and electrode degradation due to carbon formation. The simulation results are used to analyze available literature experimental data of anode-supported SOFC.

\section{Modeling and Theory for Detailed (Electro)-Chemistry, Degradation Processes and Transport}

We use a 2D model of a planar SOFC. The model includes coupled electrochemistry and transport through membrane-electrode assembly (MEA) and gas channels. Anode and cathode electrochemistry is described using elementary kinetics for all surface reactions and for charge transfer (8). Current-voltage relationships are modeled by directly solving for the electric-potential distribution in the electrodes and electrolyte taking into account the electrical double layer capacitance. The gaseous species transport within porous Ni/YSZ anodes phase is represented by two parallel transport pathways: Stefan-Maxwell flow (species fluxes due to the ordinary and Knudsen diffusion) and Darcy viscous flow (driven by species concentration and pressure). The transport of gaseous reactants to and products from surface takes place through convection and diffusion in the channel parallel to the electrode surface, described with a 1D representation of the Navier-Stokes equations (8). The evolution of carbon inside/on the anode is quantified by a multi-phase modeling approach (9). The latter is accounting for the volume fractions $(\varepsilon)$ of all phases as a function of time and spatial location inside the cell, by taking into account the chemical rate laws of all involved reactions and overall mass conservation.

Carbon species can be formed on the surface of nickel via different pathways such as hydrocarbon cracking,

$$
\mathrm{C}_{\mathrm{x}} \mathrm{H}_{\mathrm{y}}+(\mathrm{x}+\mathrm{y})(\mathrm{Ni}) \rightleftarrows \mathrm{x} \mathrm{C}_{\mathrm{Ni}}+\mathrm{yH}_{\mathrm{Ni}}
$$

hydrocarbon oxidation,

$$
\mathrm{C}_{\mathrm{x}} \mathrm{H}_{\mathrm{y}}+(\mathrm{x}+\mathrm{y}) \mathrm{O}_{\mathrm{Ni}} \rightleftarrows \mathrm{x} \mathrm{C}_{\mathrm{Ni}}+\mathrm{yOH}_{\mathrm{Ni}}
$$

Boudouard reaction,

$$
\mathrm{xCO}+\mathrm{x}(\mathrm{Ni}) \rightleftarrows \mathrm{x} / 2 \mathrm{C}_{\mathrm{Ni}}+\mathrm{x} / 2 \mathrm{CO}_{2, \mathrm{Ni}},
$$

where, $(\mathrm{Ni})$ denotes a free Ni surface site. The formation of solid carbon as new phase on top of the Ni surface is model by an elementary-kinetic reaction of ordinary surface 
adsorbed carbon species on $\mathrm{Ni}$ surface $\left(\mathrm{C}_{\mathrm{Ni}}\right)$ from reactions [1]-[3] via the following equation:

$$
\mathrm{C}_{\mathrm{Ni}} \rightleftarrows \mathrm{C}_{\mathrm{C}}^{\mathrm{X}}+(\mathrm{Ni})
$$

where, $\mathrm{C}_{\mathrm{C}}^{\mathrm{X}}$ is bulk carbon, which belongs to a newly formed phase on top of the $\mathrm{Ni}$ surface. It is know that carbon can exist in different forms, e.g. graphite, graphene, soot (6). All of these carbon types differ in chemical as well as physical properties, correspondingly if they are formed in SOFC they have different impact on (electro)chemical phenomena. In the present work we consider two types of carbon which are formed on the surface of nickel. First, the highly dense carbon which forms as the film on the nickel surface and in the vicinity of triple-phase boundary (TPB) between nickel, YSZ and gas-phase blocking surface chemical and electrochemical reactions (Fig. 1b,c). The second type of carbon is similar to soot with comparatively low bulk density which is grown on top of carbon film blocking gaseous species transport through anode porous phase (Fig. 1d).

a)

b)

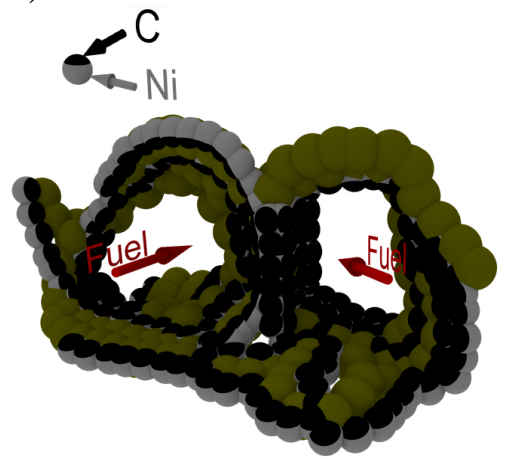

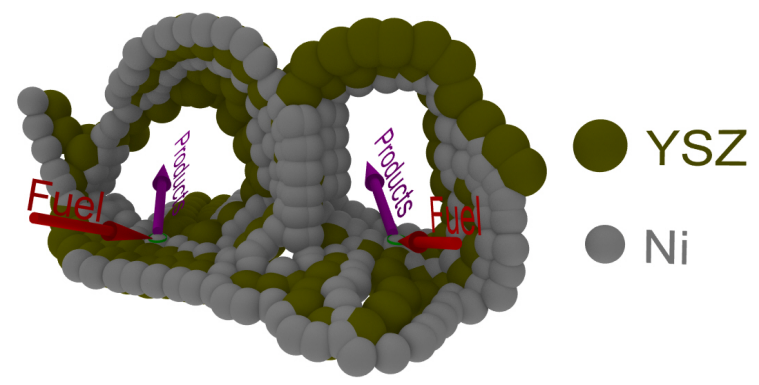

c)

d)

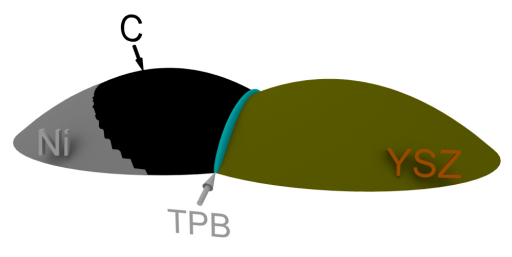

Figure 1. Schematic illustration of carbon formation at Ni/YSZ SOFC anode. a - illustration of simple anode porous phase showing inlet, surface reactions and outlet flow; $\mathrm{b}$ - formation of carbon film at Ni surface; $\mathrm{c}$ - illustration of TPB blocking, $\mathrm{d}$ - formation of soot.

The freshly formed carbon phase reduces $\mathrm{Ni}$ active surface area and TPB length. In order to describe $\mathrm{Ni}$ active area reduction as the function of carbon phase growth, we use a simple linear function as follows

$$
A_{\mathrm{Ni}}^{\mathrm{V}}=A_{\mathrm{Ni}, 0}^{\mathrm{V}} \cdot\left(1-\varepsilon_{\text {Carbon }} / \varepsilon_{\text {Carbon }}^{\max }\right),
$$


where, $A_{\mathrm{Ni}}^{\mathrm{V}}$ describes volume-specific surface area, $A_{\mathrm{Ni}, 0}^{\mathrm{V}}$ denotes initial volume specific surface area, $\varepsilon_{\text {Carbon }}$ the volume fraction of carbon phase, and $\varepsilon_{\text {Carbon }}^{\max }$ the maximum possible volume fraction of carbon phase. In the present study we use value of 0.02 for the latter parameter. Since the growth of carbon phase on Ni surface is continuously progressive, it can be assumed that anode TPB is also covered by carbon via linear equation similar to Eq. 5

$$
l_{\mathrm{Ni}}^{\mathrm{V}}=l_{\mathrm{Ni}, 0}^{\mathrm{V}} \cdot\left(1-\varepsilon_{\text {Carbon }} / \varepsilon_{\text {Carbon }}^{\max }\right) .
$$

Here, instead of volume-specific area we use volume-specific TPB length $\left(l_{\mathrm{Ni}}^{\mathrm{V}}\right)$. Both, Eqs. 5 and 6 reveal that the modeled geometrical parameter approaches zero when the volume fraction of carbon reaches its maximum value.

Geometrically newly formed carbon phase is characterized by volume fraction, density, TPB length etc. Therefore, it is reasonable to assume that TPB between carbon, nickel and gas phases (where reaction 4 takes place) would also change in time while carbon phase is growing. In the present model we assume that TPB of carbon phase increases at first, reaching appropriate maximum length, and then it decreases to zero, since, there is no more Ni surface available for carbon phase growth. This phenomenon is described by the following function

$$
l_{\text {Carbon }}^{\mathrm{V}}=l_{\text {Carbon }, 0}^{\mathrm{V}} \cdot \varepsilon_{\text {Carbon }} \cdot\left(1-\varepsilon_{\text {Carbon }} / \varepsilon_{\text {Carbon }}^{\max }\right),
$$

where, $l_{\text {Carbon }}^{\mathrm{V}}$ is the TPB length of carbon phase, correspondingly, a subscript ${ }_{0}$ denotes the initial TPB length. As it was mentioned soot phase is growing on top of carbon film via equation $\mathrm{C}_{\mathrm{C}}^{\mathrm{X}} \rightleftarrows \mathrm{C}_{\text {Soot }}$. Correspondingly, the TPB of soot phase growth increases in time being a function of carbon volume fraction

$$
l_{\text {Soot }}^{\mathrm{V}}=7 \cdot 10^{5} \cdot \varepsilon_{\text {Carbon }},
$$

where, $l_{\text {Soot }}^{\mathrm{V}}$ is the TPB length of soot phase.

\section{$\underline{\text { Simulation Procedure }}$}

Simulations were carried out using the in-house software package DENIS (detailed electro-chemistry and numerical impedance simulation) (8). In order to evaluate the chemical source terms, we use the software CANTERA developed by Goodwin and coworkers (10). We coupled CANTERA to the in-house software DENIS, making the full CANTERA functionality available during DENIS runtime. All model equations described in this paper together with other necessary (electro)-chemical and transport equations are given in detail in Ref. (8). They are represented by partial differential equations (PDE). Correspondingly, spatial derivatives of the PDE system are discretized by finite volume method which converts the initial boundary value problem into an initial value problem for a differential algebraic equation (DAE) system. The number of control volumes is chosen such, that a further increase does not affect the calculated results within $0.5 \%$ for the discretization in $x$ and $y$ dimension, respectively. An extrapolation 
method based upon semi-implicit Euler discretization is used to integrate the discretized equations system in time, as implemented in the stiff solver LIMEX (11).

Experimental electrochemical impedance spectra were simulated using a potential step and current relaxation technique (12). The impedance is obtained in the frequency domain by a Fourier transformation of the resulting time-domain traces of current and potential.

\section{Model Parameterization and Elementary Kinetic Reaction Mechanism}

\section{$\underline{\text { Model Parameterization }}$}

We use the model described above to analyze recent experiments of Chen et al., which were conducted using well-defined and thoroughly-characterized Ni/YSZ-based anode-supported SOFC (13). These experiments stand for one of the most complete data set available at the present and they cover an extended range of operating temperatures ( $923 \mathrm{~K} \leq T \leq 1023 \mathrm{~K}$ ) and various syngas compositions (see Ref. (13) for detail). In the present work we use the following gas phase composition $23.64 \% \mathrm{CH}_{4}, 7.6 \% \mathrm{CO}$, $14.27 \% \mathrm{CO}_{2}, 49.48 \% \mathrm{H}_{2}, 5 \% \mathrm{H}_{2} \mathrm{O}$ (in the Ref. (13) is marked as gas 7) for all simulations.

\section{$\underline{\text { Reaction Mechanism }}$}

Heterogeneous chemistry on $\mathrm{Ni}$ surface and charge-transfer. Since gas-phase composition used in the present work consist of methane and syngas, we use full mechanism of methane reforming on nickel surface developed previously by Deutschmann and co-workers (14). The reaction mechanism consists of 42 surface reactions among 7 gas phase species and 14 surface adsorbed species. This mechanism was developed to describe steam reforming (SR), partial oxidation and dry reforming of methane over Ni surface. All kinetic and thermodynamic data are used from the mentioned paper without any changes.

The establishment of charge transfer reaction pathways and the evaluation of their rate expressions is one the most difficult, however, one of the most important task for SOFC modeling $(15,16)$. In this study, charge-transfer reaction mechanism comprises hydrogen oxidation at TPB by oxygen anions from electrolyte given out water at anode side. There are two parameters in the rate expressions for the CT reaction, which were adjusted to find the best fit with measured voltage stability tests and impedance spectra, that is, Arrhenius pre-exponential factor $\left(k^{0}\right)$ and activation energy ( $\left.E^{\text {act }}\right)$. The values of the activation energy $\left(145 \mathrm{~kJ} \cdot \mathrm{mol}^{-1}\right)$ and pre-exponential factor $\left(8 \cdot 10^{3} \mathrm{~cm}^{2} \cdot \mathrm{mol}^{-1} \cdot \mathrm{s}^{-1}\right)$, that are found to best represent all experimental measurements, are adjusted according to the temperature dependency of complex impedance. Although the charge-transfer reaction involves two electrons, the symmetry factor $\alpha$ is assumed to be 0.5 . However, it shall be noted that the modeling results are sensitive to the values of the symmetry factor, we decided to fix it to the value of 0.5 in order to reduce the number of fitting parameters.

Kinetic and thermodynamic data of solid carbon phase. As described above (Eq. 4), carbon phase on Ni surface is formed by agglomeration of ordinary carbon species to the new phase. Hence, it is essential to derive thermodynamic data of deposited carbon in the 
new phase. There are many studies on analysis of thermodynamic properties of carbon formation in SOFC (17-19), however, all of them are based upon an assumption that thermodynamic properties of graphite represent all types of carbon formed at Ni/YSZ anode. Many electrochemical and chemical experimental results contradict this assumption, suggesting that thermodynamic properties of carbon, belonging to the newly formed phase on $\mathrm{Ni}$ surface, must be determined separately. Efforts to determine thermodynamic properties of deposited carbon were made by Hill and co-workers $(20,21)$, and recently by Lee et al. (7).

Following this work we have derived thermodynamic data (enthalpy and entropy) and kinetics of carbon deposited in the new phase on Ni surface described by Eq. 4. To this goal, we used temperature-programmed oxidation (TPO) measurements by AlzateRestrepo et al. (20). Using our model we have performed TPO simulations (Fig. 2) and fitted parameters to the literature experiments. For the simulation of carbon formation via Eq. 4, the pre-exponential factor of $5.5 \cdot 10^{16} \mathrm{~cm}^{2} \cdot \mathrm{mol}^{-1} \cdot \mathrm{s}^{-1}$ along with an activation energy of $30 \mathrm{~kJ} \cdot \mathrm{mol}^{-1}$ were obtained as well as values for solid carbon enthalpy and entropy of $-91.2 \mathrm{~kJ} \cdot \mathrm{mol}^{-1}$ and $32 \mathrm{~J} \cdot \mathrm{K}^{-1} \cdot \mathrm{mol}^{-1}$, respectively.

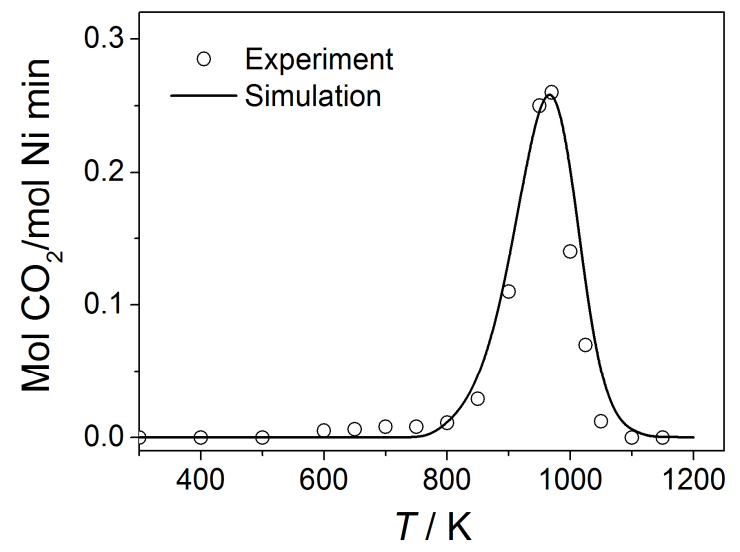

Figure 2. Comparison between experimental (Ref. (20)) and simulated TPO spectra of a $\mathrm{Ni} / \mathrm{YSZ}$ anode exposed to $\mathrm{CH}_{4}$ for $6 \mathrm{~h}$ at $1073 \mathrm{~K}$ at OCV. Heating rate is $10 \mathrm{~K} \cdot \mathrm{min}^{-1}$.

\section{Results and Discussion}

This section shows the comparison between our simulations and experiments by Chen et al. (13) for a temperature of $1023 \mathrm{~K}$ (first subsection) and a temperature of $923 \mathrm{~K}$ (second subsection).

SOFC performance at $1023 \mathrm{~K}$. Figure 3 shows the comparison between experimentally measured OCV and our simulations for temperature of $1023 \mathrm{~K}$ for 10 hours. This is especially valuable data because it shows the influence of degradation phenomena on the cell performance. Using our model we observe a quantitative agreement between simulation and experiment over the complete investigated time range. 


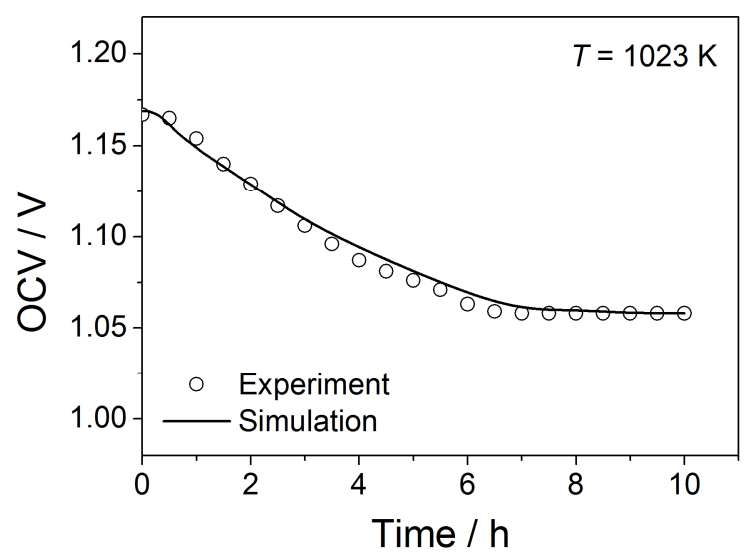

Figure 3. Comparison between experimental and simulated cell stability at OCV and temperature of $1023 \mathrm{~K}$, the experimental results are taken from Ref. (13).

Fig. 4 shows the comparison between experimental and simulated impedance spectra for $T=1023 \mathrm{~K}$. As described by Chen et al. (13), three different impedance spectra were recorded at three different times during the OCV stability test shown in Fig. 3. For each time, both Nyquist and Bode simulated plots are shown. Experiments were taken at 15 minutes, 30 minutes and 45 minutes. As within the first 45 minutes, simulations shows no significant change (cf. Figure 3), we compare these experiments to simulations at 21 minutes, 42 minutes and 65 minutes. It was only possible to observe a qualitative agreement between model and experiment over the complete investigated range of experimental conditions using these different time ranges.
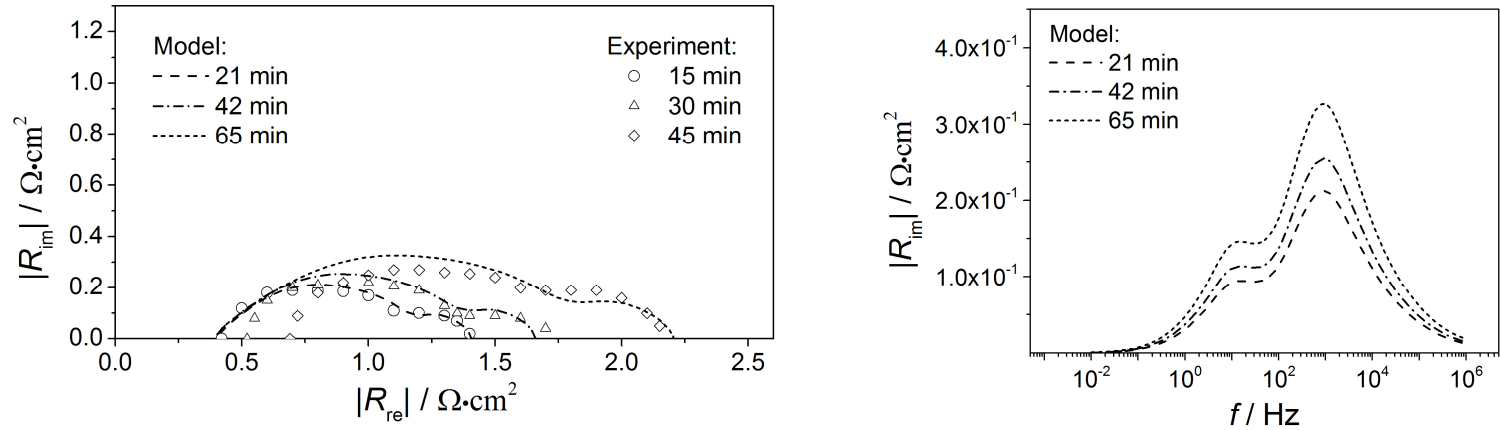

Figure 4. Nyquist (left) and Bode (right) plots of simulated impedance spectra at temperature of $1023 \mathrm{~K}$ and pressure $1 \mathrm{~atm}$, the experimental results are taken from Ref. (13).

The simulation allows to monitor spatiotemporal evolution of carbon-phase formation during the OCV stability simulation shown in Fig. 3. Figure 5 illustrates the change of solid carbon concentration at nickel surface at time points of 21 minutes, 42 minutes, 65 minutes (corresponds to the three impedances simulations) and 10 hours. The simulation reveals a spatially inhomogeneous formation of solid carbon through the anode thickness. After 10 hours the complete Ni surface is covered with solid carbon, which increases up to the limit of $\varepsilon^{\max }$ Carbon $=0.02$ (cf. Eq. 5). 

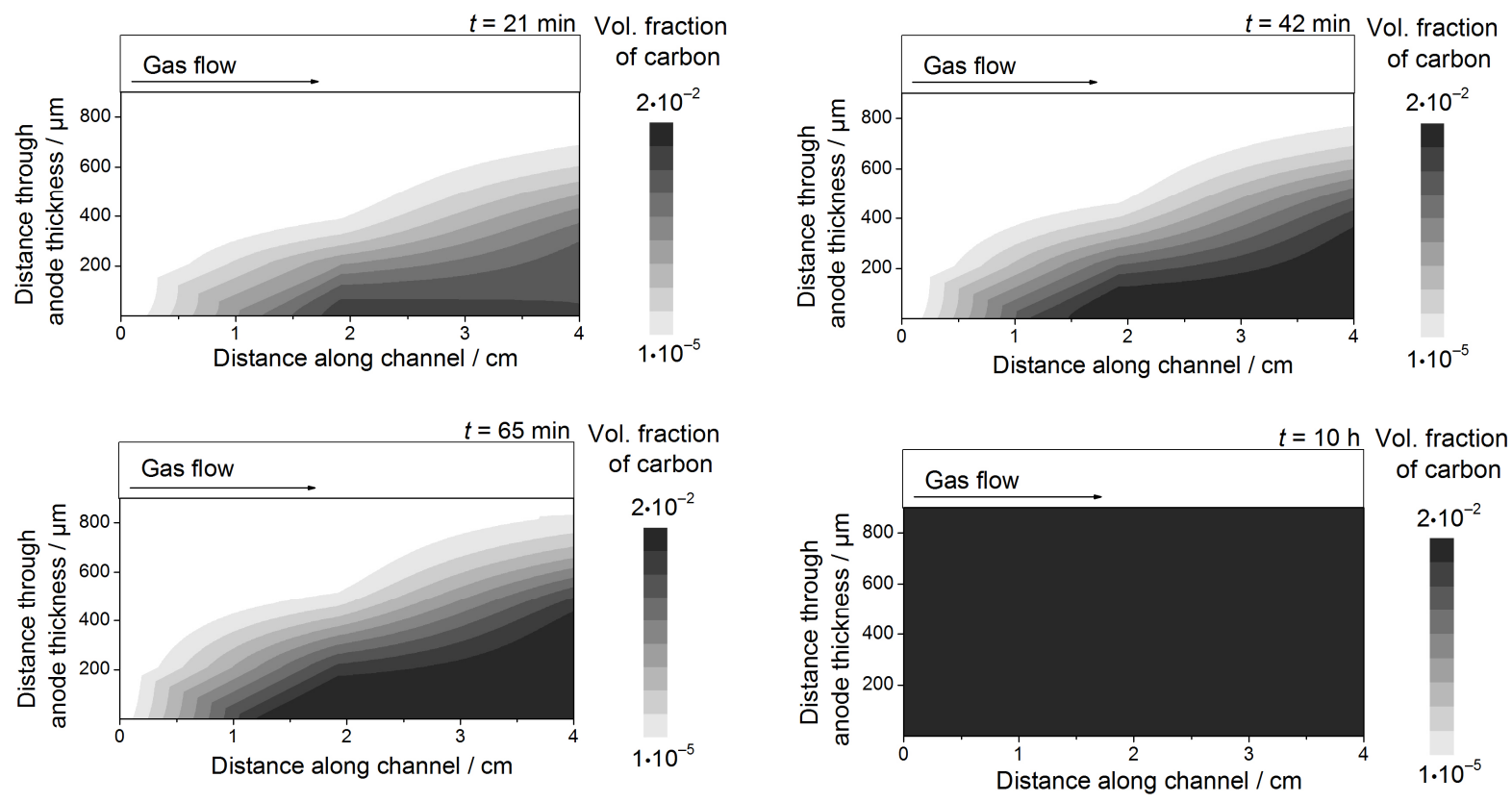

Figure 5. Spatial evolution of carbon formation inside the porous anode at four different times corresponding to the simulation shown in Fig. 3 ( $T=1023 \mathrm{~K})$.

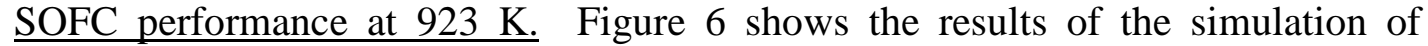
voltage stability test at $923 \mathrm{~K}$ over 10 hours similar to the results for $1023 \mathrm{~K}$ shown in Fig. 3 . There are no experimental results available for this temperature. However, following Fig. 6 it could be concluded that cell performance, predicted by our model for temperature $923 \mathrm{~K}$, is physically reasonable for these conditions. This is because, OCV predicted for time zero is approximately by $0.03 \mathrm{~V}$ lower than OCV at $1023 \mathrm{~K}$ (see Fig. 3 ), which stays in a good agreement with prior literature where it was shown experimentally that OCV of SOFC operated with hydrocarbons increases with increasing temperature (22).

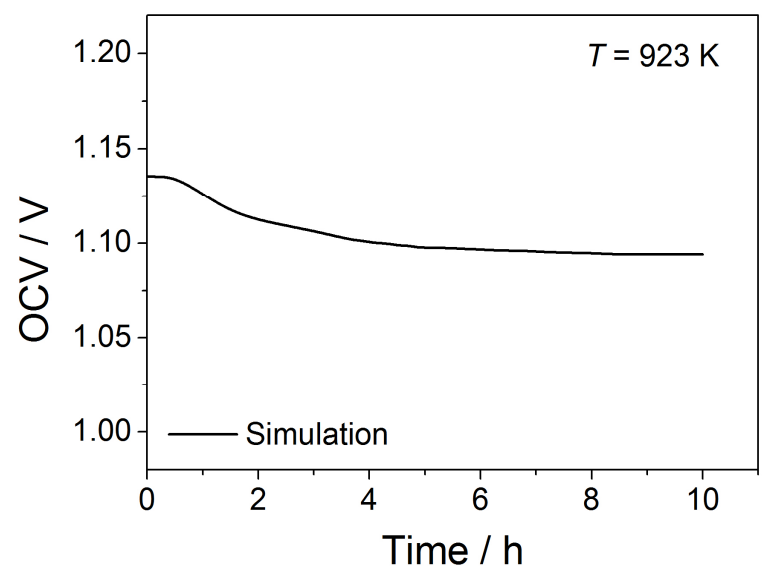

Figure 6. Theoretically predicted OCV cell stability at temperature of $923 \mathrm{~K}$.

Simulated and experimental impedance spectra at $923 \mathrm{~K}$ are shown in Fig. 7. Here, again we obtain a qualitative agreement of the model with experimental measurements at different times. In the simulation two semi-circles at high and low frequencies are observed, which corresponds to anode surface chemistry/electrochemical double layer and combined porous/channel gas transport, respectively. 

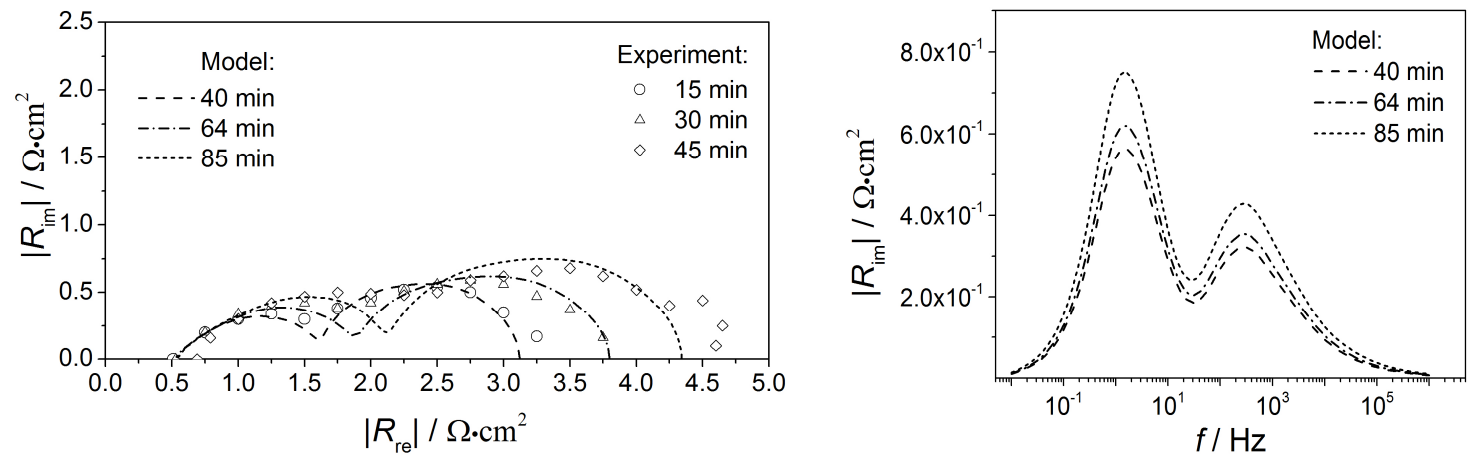

Figure 7. Nyquist (left) and Bode (right) plots of simulated impedance spectra at temperature of $923 \mathrm{~K}$ and pressure $1 \mathrm{~atm}$. The experimental results are taken from Ref. (13).

Figures 8 and 9 illustrate carbon film and soot evolution, respectively. The model predicts that the amount of carbon film (Fig. 8) formed at $973 \mathrm{~K}$ is much less than at higher temperature (Fig. 5). There are two reasons for this: $(i)$ since at lower temperature more water is formed in the reforming equilibrium, part of the carbon film is oxidized to carbon monoxide via the following reaction $\mathrm{C}+\mathrm{H}_{2} \mathrm{O} \rightleftarrows \mathrm{CO}+\mathrm{H}_{2}$, and (ii) carbon film continues reacting at lower temperature to yield soot (Fig. 9). Similar to carbon film, soot is formed firstly close to anode/electrolyte boundary and then progressively fills complete anode porous phase.
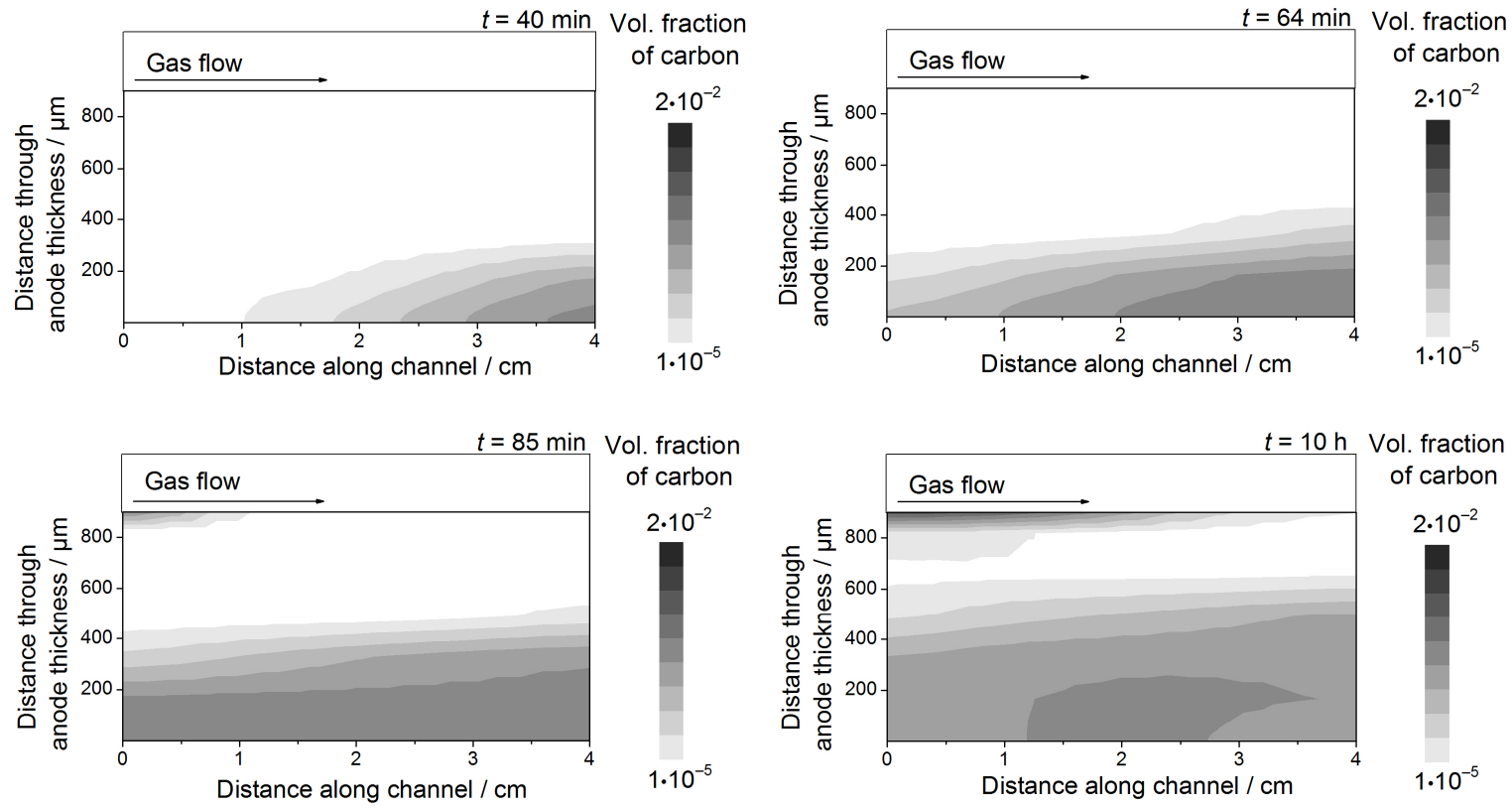

Figure 8. Spatial evolution of carbon formation inside the porous anode at four different times corresponding to the simulation shown in Fig. $6(T=923 \mathrm{~K})$. 

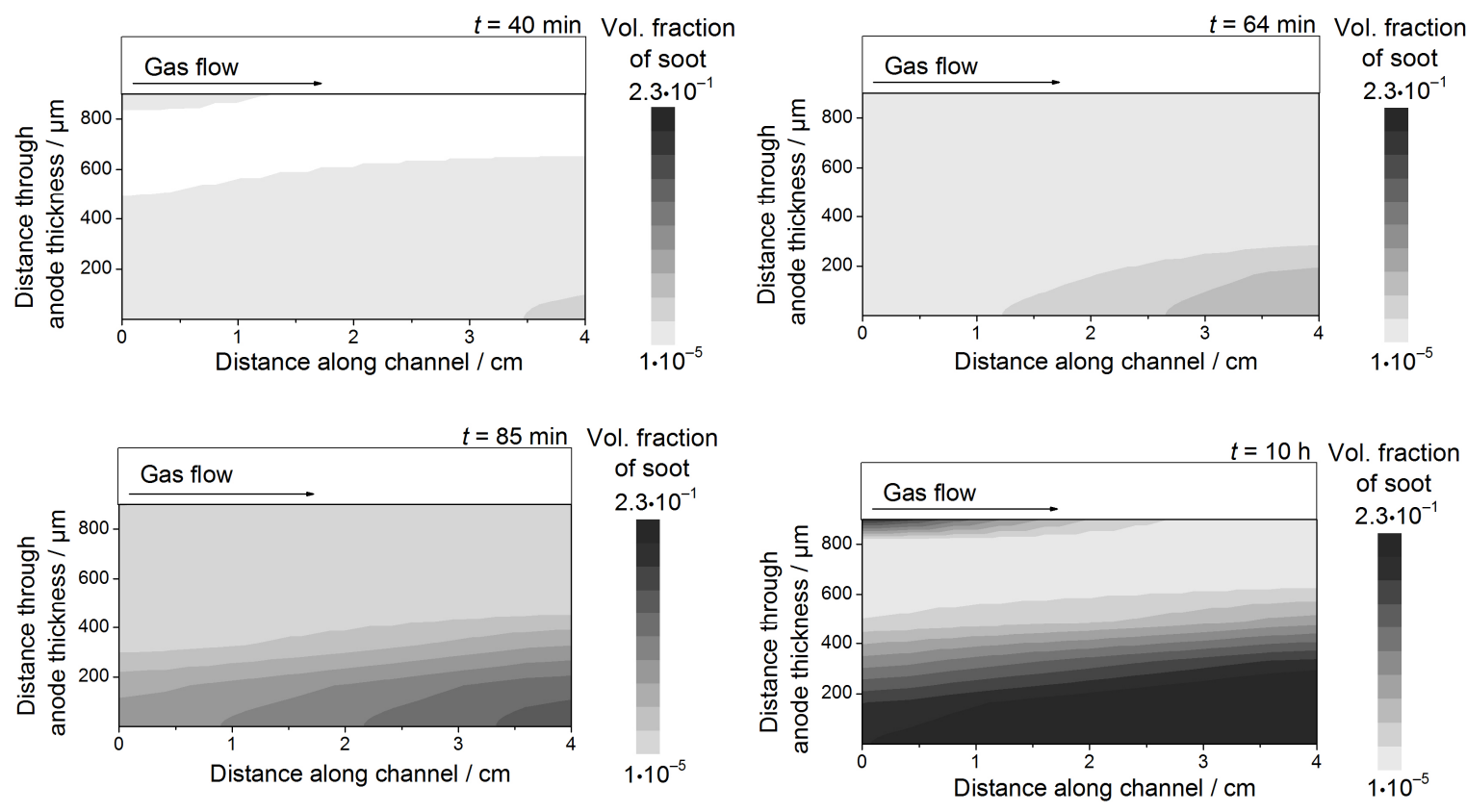

Figure 9. Spatial evolution of soot formation inside the porous anode at four different times corresponding to the simulation shown in Fig. $6(T=923 \mathrm{~K})$

Since soot has a lower density than carbon film, it fills large fractions of the available pore space, thereby blocking transport of gaseous species. Correspondinglly, pressure inside the anode increases drasticly (numerical results are not shown here due to article's size restriction).

\section{Conclusions}

We have presented a modeling study of Ni/YSZ SOFC anode degradation due to solid carbon formation. The presented model combines the effect of porous and channel flow, heterogeneous chemistry, electrochemistry, and degradation phenomena in SOFC operating on $\mathrm{CH}_{4} / \mathrm{CO} / \mathrm{CO}_{2} / \mathrm{H}_{2} / \mathrm{H}_{2} \mathrm{O}$ mixture. Different experimental data taken from literature were successfully reproduced over a wide range of operating conditions. An elementary kinetic description is used throughout the paper, which opens up the possibility of a direct mechanistic interpretation of the experimentally-observed electrochemical performance of Ni/YSZ SOFC anodes.

This paper shows simulations at open circuit conditions only. Simulations under cell polarization at different temperatures, including the effect of nickel dusting, are subject of ongoing investigations.

\section{References}

1. S.C. Singhal and K. Kendall, High Temperature Solid Oxide Fuel Cells: Fundamental, Design and Applications, Elsevier Advanced Technology, Oxford, UK (2003).

2. S. McIntosh and R.J. Gorte, Chemi. Reviews, 104 (10), 4845 (2004).

3. M. Ni, Int. J. Hydrogen Energy, 38 (6), 2846 (2013). 
4. D. Mogensen, J.-D. Grunwaldt, P.V. Hendriksen, K. Dam-Johansen and J.U. Nielsen, J. Power Sources, 196 (1), 25 (2011).

5. B.R. Alexander, R.E. Mitchell and T.M. Gür, J. Power Sources, 228, 132 (2013).

6. C.H. Bartholomew, Cat. Rev.-Sci. Eng., 24 (1), 67 (1982).

7. W.Y. Lee, J. Hanna and a. F. Ghoniem, J. Electrochem. Soc., 160 (2), F94 (2012).

8. W.G. Bessler, S. Gewies, M. Vogler, Electrochim. Acta, 53 (4), 1782 (2007).

9. J.P. Neidhardt, D.N. Fronczek, T. Jahnke, D. Danner, B. Horstmann and W.G. Bessler, J. Electrochem. Soc., 159 (9), A1528 (2012).

10. D. Goodwin, Cantera: An Object-oriented Software Toolkit for Chemical Kinetics, Thermodynamics, and Transport Processes, Caltech, Pasadena, http://code.google.com/p/cantera (2009).

11. P. Deuflhard, E. Hairer and J. Zugck, Numerische Mathematik, 51, 501 (1987).

12. W.G. Bessler, Solid State Ionics, 176 (11-12), 997 (2005).

13. T. Chen, W.G. Wang, H. Miao, T. Li and C. Xu, J. Power Sources, 196 (5), 2461 (2011).

14. L. Maier, B. Schädel, K. Herrera Delgado, S. Tischer and O. Deutschmann, Top. Catal., 54 (13-15), 845 (2011).

15. D.G. Goodwin, H. Zhu, A.M. Colclasure and R.J. Kee, J. Electrochem. Soc., 156 (9), B1004 (2009).

16. C.J. Moyer, N.P. Sullivan, H. Zhu and R.J. Kee, J. Electrochem. Soc., 158 (2), B117 (2011).

17. J.-H. Koh, B.-S. Kang, H.C. Lim and Y.-S. Yoo, Electrochem. Solid-State Lett., 4 (2), A12 (2001).

18. J. Liu and S.A. Barnett, Solid State Ionics, 158, 11 (2003).

19. K. Sasaki and Y. Teraoka, J. Electrochem. Soc., 150 (7), A885 (2003).

20. V. Alzate-Restrepo and J.M. Hill, Appl. Cat. A: General, 342 (1-2), 49 (2008).

21. V. Alzate-Restrepo and J.M. Hill, J. Power Sources, 195 (5), 1344 (2010).

22. Y. Lin, Z. Zhan and J. Liu, S. Barnett, Solid State Ionics, 176 (23-24), 1827 (2005). 